\title{
Effects of Empowering Leadership on Employee Voice Behavior: The Mediating Role of Psychological Empowerment
}

\author{
Jesse Jackson Makwetta ${ }^{*}$, Yao Deli, Francis Atta Sarpong, Victor Sifameni Sekei, \\ Khurram Zaman Khan, Megan Emfosi Meena
}

School of Economics and Management, Anhui University of Science and Technology, Huainan, China

Email address:

jmakwetta@yahoo.com (J. J. Makwetta),dlyaodym@163.com (Yao Deli), nanaipee@gmail.com (F. A. Sarpong), victor.sekei@hotmail.com(V.S. Sekei),khurramzk@outlook.com (K. Z. Khan),megan.meena17@gmail.com (M. E. Meena)

*Corresponding author

\section{To cite this article:}

Jesse Jackson Makwetta, Yao Deli, Francis Atta Sarpong, Victor Sifameni Sekei, Khurram Zaman Khan, Megan Emfosi Meena. Effects of Empowering Leadership on Employee Voice Behavior: The Mediating Role of Psychological Empowerment. Psychology and Behavioral Sciences. Vol. 10, No. 4, 2021, pp. 125-133. doi: 10.11648/j.pbs.20211004.11

Received: June 8, 2021; Accepted: June 24, 2021; Published: July 13, 2021

\begin{abstract}
Over the past two decades many organizations are moving towards decentralization approach and hence putting in much effort to ensure that employees acquire the necessary leadership skills. Many organizations have adopted managerial attempts that aim to strengthen and empower leaders to boost organizational performance. Several educational researchers have exploited the relationship that exist between empowering leadership, psychological empowerment. The purpose of this research was to analyze the effects that empowering leadership can have on employee voice behavior, with the mediating role of psychological empowerment. The technique used to gather responses from 151 respondents was mainly quantitative research approach with questionnaires as a tool. The study employed random sampling to involve respondents in the study. Multiple operations such as correlation matrix, regression analysis and bootstrap approach were conducted to analyze data collected from the questionnaire. The findings showed a positive correlation between the variables measured. All hypotheses tested revealed a significant positive relationship between empowering leadership and voice behavior, psychological empowerment and voice behavior, and the mediating role of psychological empowerment. This study is useful in the academic, industrial and organizational sector. Organizations can use it to employ empowering leadership and measure the change in the behavior of employees, attitude, motivation, and empowerment. In terms of academia, this research opens more doors to further investigate the relationship between these variables. The limitations of the study include purely quantitative means of analysis and the use of random sampling. Future researchers can get more insights by employing a qualitative technique and adding more variables to further define the relationship and get better insights.
\end{abstract}

Keywords: Empowerment Leadership, Voice Behavior, Psychological Empowerment

\section{Introduction}

Over the past few years, technological advances have taken over the world with the speed of light. Just as the world develops itself in the field of technology, so does it incorporate managerial advances in its system? Organizations are now moving from previously being centralized to decentralization and putting more efforts in order to ensure the betterment of the workforce and to motivate them intrinsically to get better performance outcomes. This is giving rise to different managerial approaches that address these problems and provide a solution. The most recent management practices that have taken shape and is rising to prominence in organizations as well as in research, is empowering leadership.

The purpose of implementing and empowering leadership in any organization is to empower the employees psychologically, which can, therefore, lead to the employees becoming intrinsically motivated in themselves and in the job they do. Even though this is the theoretical implication and 
the desired result of implementing such a leadership, its success depends entirely on the individuals who are equipped to effectively deliver these practices [1]. Empowering leadership, at its heart, is based on sharing the power with the firm's employees to increase their drive and their investment in their jobs [2].

Sufficient research is available regarding the relationships between empowering leadership, psychological empowerment and their result in organizations and its employees, be it behavioral or attitudinal. Their impact has been related to a number of outcomes such as job satisfaction, employee motivation, organizational commitment etc. The research relates empowering leadership to employee voice behavior, with the mediating role of psychological empowerment of employees. Looking at the theoretical determinants of empowering leadership and psychological empowerment, i.e., power sharing, motivation, support etc. it is safe to assume that such an environment will have a positive impact upon the voice behavior of employees.

Voice behavior is another research topic that has attracted attention in the past few years [3-6]. It has been correlated with many favorable outcomes such as competitive advantage and organization success [7-10]. Importance of exhibiting voice behavior can have two benefits i.e., organizational and individual. In the organizational context, exhibiting voice behavior can lead to more visibility of operations as well as better assessment of justice [11]. In the individual context, it helps employees to perform their duties better while also keeping job stress at bay [5, 12].

Therefore, the research will be measuring how empowering leadership helps employees by sharing their power with them and giving the employees some sort of autonomy in their jobs. Moreover, the study investigates how the various kind of leadership affects the mental states of the employees and they get more empowered under this kind of leadership. Also the study looks at the kind of effect an empowered psychological state has on the voice behavior of the employees and whether they feel comfortable voicing out their concerns and challenging their environment for something innovative.

\section{Literature Review}

\subsection{Empowering Leadership (EPL)}

According to [13] empowering leadership mainly comprises the leaders of the firm participating actively in mentoring their employees, giving them free will to make their own decisions and specify their own goals, training them, sharing information, and supporting them emotionally. The capabilities of the leaders themselves play a huge role in the success of empowering leadership and imparting knowledge and traits unto their employees. This leadership focuses on helping the employees to lead themselves rather than having a boss over them telling them what to do [14].

Empowerment initially debuted in the management field in 1980 s, and according to [15], the reason for this was the need to make employees more productive compares to other changes that were taking place in the business environment such as technological and commercial revolution [16, 17]. Employing these changes in businesses led the organizations to have closer relationships with their customers and clients, efficiency, improved quality, and decentralized and flexible organizational design. According to [18], the industries of the world are shifting towards more knowledge workers and have become more complex in the past 20 years. The companies are now requiring more and more educated workforce that can tackle anything thrown at them [19].

Empowering leadership is grabbing more and more attention as the focus of organizations and academia alike are moving from traditional forms of leadership such as transactional, transformational, laissez-faire etc. [20]. Therefore, in simple words, empowering leadership can be defined as the form of leadership that focuses on sharing power, responsibility and authority with subordinates [21-23].

\subsection{Psychological Empowerment (PE)}

The definition of psychological empowerment that has been widely accepted and quoted is that of [24]; hence, psychological empowerment can be seen as an immense intrinsic motivation which leads to one believing that they have greater control over their surroundings and of their work and are more proactive. Psychological empowerment can be broken down into four dimensions namely meaning, competence, self-determination and impact. There dimensions are discussed below:

\subsubsection{Meaning}

Meaning relates to an individual's own perception of work or purpose and how it relates to their ideals [23]. The more meaningful a person finds a task to be, the more he/she will be willing to do it and the more psychologically empowered he/she will be. It relates the beliefs and values of an individual to the work requirements [25-26]

\subsubsection{Competence}

Competence is defined as an individual's perception of his/her own capabilities and skill sets to perform a certain task [27]. Competence can also be used in terms of selfefficacy or self-esteem.

\subsubsection{Self-determination}

Self-determination, here, is used in terms of autonomy and having a choice regarding any work or actions [28]. Autonomous behavior in a work environment may include personal decisions regarding how much effort to exert in a certain task, what pace to be set etc. [29-30].

\subsubsection{Impact}

Impact refers to how much of strategic and administrative decisions an individual can influence [31]. It is the opposite of helplessness [32].

\subsection{Voice Behavior (VB)}

Van Dyne \& LePine [33] describe voice behavior as somewhat of an encouragement of employees so they can 
take up constructive challenges for their improved performance; moreover, they have also defined it as the behavior of employees that leads them to make some constructive changes and challenge the status quo of the workplace. It is a behavior that leads to an improved working environment for the employees which is driven by construction-oriented communication. A lot of studies focus on the topic of employees and their empowerment that can help them take initiative [11].

Research in voice behavior has implications and importance for individuals and organizations alike. In individuals, having a voice behavior reduces and diminishes the stress of the job and enhances their performance on the job $[5,12]$ has also positively correlated voice behavior with performance of employees. In terms of organizations, employees can rest assured of the justice of the company if they are encouraged to give their own advice on different matters [5]. Moreover, [34] is of the opinion that it is positively correlated to having an improved sense of control over one's own job and satisfaction thereof. Therefore, more and more studies are being conducted on this topic since it attracts the attention of both the organizations as well as the academia. As the organizational landscape changes, so does its practices; and incorporating employee voice behavior into organization structures can result in benefits to the organization.

\section{Hypothetical Framework}

To analyze the effect empowering leadership has on voice behavior of employees, with psychological empowerment as a mediating variable; the study proposes the following hypothetical model in Figure 1:

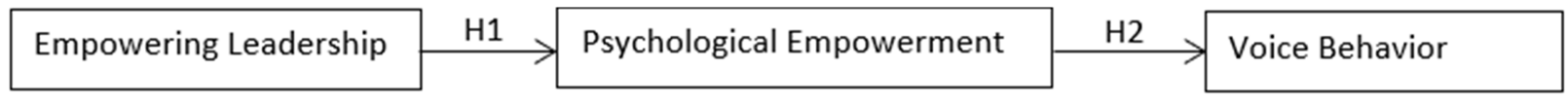

Figure 1. Hypothetical Framework.

\subsection{Effect of Empowering Leadership on Psychological Empowerment}

One aspect of an empowering leader is to make employees aware of their goal in the firm, which can help the employees to assess their job regarding how it relates to the overall goal, hence, finding meaning in their work [35]. Moreover, [35] is of the opinion that empowering leaders tend to encourage their employees and share their power with them, therefore, granting them autonomy over their decisions regarding their jobs, which can lead the employees to believe that they have some sort of impact over how things are run and have a better sense of self-esteem. [36] Believes that empowering leaders also act as coaches to their employees as well as they lead by example, which can help employees feel more confident in their work and believe they are competent enough to carry out their job demands. Hence, different studies validate the positive correlation between empowering leadership and psychological empowerment of employees [37-39]. The research first hypothesis is as follows:

H1: Empowering leadership is positively related to psychological empowerment.

\subsection{Effects of Psychological Empowerment on Voice Behavior}

When an employee is empowered mentally, they have a more positive outlook on their job and role in an organization. It offers internal motivation to the employees [24]. Moreover, the four factors involved in psychological empowerment, namely meaning, competence, selfdetermination, and impact, are known to provide positive results [40]. Employees find more meaning in their work; and are supported by their management. This support in turn leads to the employees having a voice for their concerns and the concerns of the organization overall. The research hypothesis proposes a positive relationship between the two variables based on the theoretical assumption that when employees are psychologically empowered, they work rigorously towards the collective goal of an organization and have an increased say in the decisions involved, whether they are on a day-to-day basis or on a larger scale. This also develops a better understanding of one's superior and employees know to which extent they are able to make their own decisions and choices [41]. Therefore, this leads to the research second hypothesis, i.e.:

H2: Psychological empowerment is positively related to voice behavior.

\subsection{Psychological Empowerment as a Mediating Variable Between EPL and $V B$}

A number of studies have been focusing on the role of psychological empowerment as a mediating variable among different variables, especially in the context of workplace [42]. The extent of psychological empowerment depends largely upon the type of leadership employed in an organization. The supportive attitude of the leaders and the level of autonomy provided to the employees greatly determine the level of psychological empowerment among the employees [35, 43-44] is of the opinion that the greater the employees think they have control over their performance and output of work, the more they are likely to exhibit voice behavior. Moreover, an empowering leader motivates employees to show autonomy in their work, which helps employees to voice out their thoughts $[35,38,45]$. They help their employees to see the bigger picture and the goal of the organization, which helps them to envision how their work is contributing to the bigger picture $[38,46]$. This leads the research to its third hypothesis:

H3: Psychological empowerment acts as a significant mediator between empowering leadership and psychological empowerment.

The mediating role of psychological empowerment is displayed in Figure 2. 


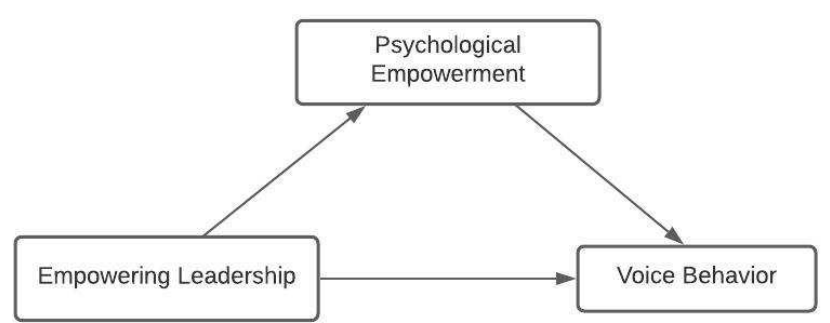

Figure 2. Mediating Role of Psychological Empowerment.

\section{Methodology}

\subsection{Overview}

The study adopted random sampling as a sampling technique in selecting 160 respondents for the study. The method employed for gathering and analysis of data was purely quantitative. Out of the 160 questionnaires distributed out to respondents, only 151 were rightly filled and usable for data analysis. Among the respondents, 57\% were male and $43 \%$ were female. The work experience of the respondents fell mainly in the range of $1-5$ years $(81.5 \%)$ followed by 11 years and above (9.9\%) and finally 6-10 years $(8.6 \%)$ as presented in Table 1 .

\subsection{Questionnaire Design and Measure}

\subsubsection{Empowering Leadership}

The study used the scale introduced by Amundsen and Martinsen to measure empowering leadership [47]. It comprised of 24 items with 7-point Likert response scale from $1=$ Never to $7=$ Always.

\subsubsection{Psychological Empowerment}

The scale used for measuring psychological empowerment was that of [24]. It was based on 12 items with a 7-point Likert response scale ranging from $1=$ strongly disagree to $7=$ strongly agree.

\subsubsection{Voice Behavior}

The scale for voice behavior of employees was taken from [4]. It consisted of a total of 6 items with 6-point Likert scale ranging from $1=$ strongly disagree to $6=$ strongly agree.

\section{Results and Discussion}

\subsection{Overview}

The descriptive profile of the respondents is given below in Table 1.

Table 1. Background Information of Respondents.

\begin{tabular}{|c|c|c|c|c|}
\hline Attribute & Frequency & Percent & Valid Percent & Cumulative Percent \\
\hline \multicolumn{5}{|l|}{ Gender } \\
\hline Male & 86 & 57.00 & 57.00 & 57.00 \\
\hline Female & 65 & 43.00 & 43.00 & 100.00 \\
\hline Total & 151 & 100.00 & 100.00 & \\
\hline \multicolumn{5}{|c|}{ Educational Background } \\
\hline No college degree & 2 & 1.30 & 1.30 & 1.30 \\
\hline Diploma & 11 & 7.30 & 7.30 & 8.60 \\
\hline Bachelor's degree & 98 & 64.90 & 64.90 & 73.50 \\
\hline Master's degree & 37 & 24.50 & 24.50 & 98.00 \\
\hline $\mathrm{PhD}$ & 3 & 2.00 & 2.00 & 100.00 \\
\hline Total & 151 & 100.00 & 100.00 & \\
\hline \multicolumn{5}{|l|}{ Age } \\
\hline $16-20$ & 2 & 1.30 & 1.30 & 1.30 \\
\hline $21-25$ & 47 & 31.10 & 31.10 & 32.50 \\
\hline $26-30$ & 72 & 47.70 & 47.70 & 80.10 \\
\hline $31-35$ & 8 & 5.30 & 5.30 & 85.40 \\
\hline $36-40$ & 6 & 4.00 & 4.00 & 89.40 \\
\hline $41-45$ & 4 & 2.60 & 2.60 & 92.10 \\
\hline $46-50$ & 6 & 4.00 & 4.00 & 96.00 \\
\hline Above 50 & 6 & 4.00 & 4.00 & 100.00 \\
\hline Total & 151 & 100.00 & 100.00 & \\
\hline \multicolumn{5}{|l|}{ Work Experience } \\
\hline $1-5$ years & 123 & 81.50 & 81.50 & 81.50 \\
\hline $6-10$ years & 13 & 8.60 & 8.60 & 90.10 \\
\hline 11 and above & 15 & 9.90 & 9.90 & 100.00 \\
\hline Total & 151 & 100.00 & 100.00 & \\
\hline
\end{tabular}

Table 2. Test of Validity.

\begin{tabular}{lll}
\hline Test & Measure & Estimate \\
\hline Kaiser-Meyer-Olkin Measure of Sampling Adequacy & & 0.924 \\
& Approx. Chi-square & 6254.252 \\
Bartlett's Test of Sphericity & df & 861 \\
& Sig. & 0.000 \\
\hline
\end{tabular}

The factor analysis test was conducted to prove the validity and reliability of the questionnaire. The table for the 
test of Validity is given in Table 2. In order to test validity and reliability of research constructs, Kaiser-Meyer-Olkin (KMO) and Bartlett's Test of Sphericity were used. The KMO measure the conciseness of the answers to the questionnaire. [48] Requires at least a KMO value of 0.5 for satisfactory factor analysis to take place. The Bartlett's test, a test of Sphericity measures the overall strength of relationships among variables. Therefore, a P-value less than
0.05 signify that the correlation matrix is an identity matrix. The result in Table 2 shows that minimum KMO value was 0.924, which had a high statistical significance. This indicates that all conditions have been attained for factor analysis. The results of factor analysis indicate the extraction of 6 factors, and the variance proportions of each factor were satisfactory. As observed, 6 factors account for $73.20 \%$ of the variance (or Variations).

Table 3. Correlation Matrix

\begin{tabular}{|c|c|c|c|c|c|}
\hline \multirow{2}{*}{ Variable } & \multicolumn{5}{|c|}{ Correlation Matrix } \\
\hline & Mean & Std. Dev. & 1 & 2 & 3 \\
\hline Empowering Leadership & 126.75 & 29.30 & $0.970(24)$ & & \\
\hline Psychological Empowerment & 71.34 & 11.61 & $0.606 * *(0.000)$ & $0.928(12)$ & \\
\hline Voice Behavior & 30.19 & 5.77 & $0.520 * *(0.000)$ & $0.702 * *(0.000)$ & $0.900(6)$ \\
\hline
\end{tabular}

Note: ** Significant correlation at the 0.01 level (2-tailed). Cronbach's Alpha values are presented in the diagonal. The number of measured items is presented in the parenthesis in the diagonals

The results of correlation matrix are displayed in Table 3. The statistical relationship between two continuous or quantitative variables can be described using the Pearson coefficient of correlation [49]. This test statistics employs the covariance technique, which provides magnitude and direction of relation to calculate the relationship between the two continuous variables of interest [50]. In accordance with [51] and [52], there is a moderate interaction between variables, as shown in Table 3, according to the general criteria for determining the magnitude and direction of the correlation coefficient. There is no issue of multi-collinearity since none of the estimated correlation coefficients in Table 3 are more than 0.80 [53]. As set out in Table 3 diagonals, the Cronbach's Alpha Coefficients surpass the agreed minimum threshold of 0.70 [54]. This indicates that the questionnaire is internally consistent and accurate and reliable.

\subsection{Mediation Analysis Using Baron and Kenny (1986) Method}

This research employs the use of [55] approach to simple mediation analysis. The analysis method proposed by [55] involves 4 key steps of regression analysis. The procedure used in the research is presented in Figure 3 and outlined below:

Regression Equations

$$
\begin{gathered}
P E=\text { intercept }_{1}+\mathrm{a}(\mathrm{EPL})+e_{1} \\
V B=\text { intercept }_{2}+c^{\prime}(\mathrm{EPL})+\mathrm{b}(\mathrm{PE})+e_{2}
\end{gathered}
$$

$$
V B=\text { intercept }_{3}+c(\mathrm{EPL})+e_{3}
$$

Where a, b, c, c' represent regression coefficients and e represents the error terms

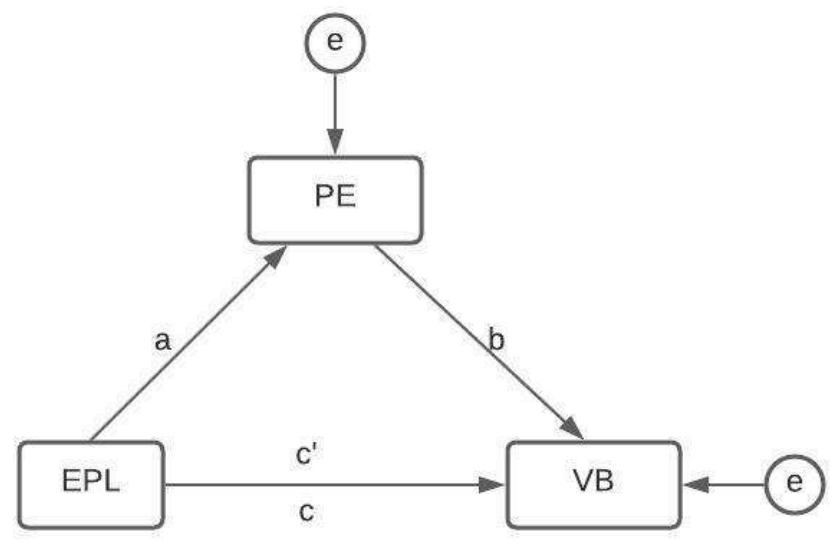

Figure 3. Regression framework as proposed by Baron and Kenny (1986).

Step 1: The study estimated the total effect between the independent variable (Empowering Leadership) and the dependent variable (Voice Behavior). This preliminary direct effect between EPL and VB is done to estimate the level of association between the two variables. It also gives information whether the mediation effect is full or partial mediation. The result of coefficient estimate is presented in Table 4.

Table 4. Coefficient Estimate of bivariate regression of EPL on VB.

\begin{tabular}{lllll}
\hline Variables & Estimate & Std. Error & T Value & Sig. Value \\
\hline Constant & 17.193 & 1.792 & 9.595 & 0.000 \\
Empowering Leadership & 0.103 & 0.014 & 7.440 & 0.000 \\
\hline
\end{tabular}

Dependent variable: Voice Behavior (VB)

Step 2: The study performed a bivariate regression between the independent variable (EPL) and the mediator variable (PE). This analysis is done to obtain the path estimate denoted by in Figure 3. The result of coefficient estimation is presented in Table 5. The results also reveal a positive relationship between Empowering leadership and Voice behavior with an estimate of 0.103 . The direct effect between these two variables is statistically significant with a P-value of 0.000 . Hence supports the research hypothesis one and concludes that empowering 
leadership is significantly correlated to Psychological empowerment.

Table 5. Coefficient Estimate of bivariate regression of EPL on PE.

\begin{tabular}{lllll}
\hline Variables & Estimate & Std. Error & T Value & Sig. Value \\
\hline Constant & 40.914 & 3.360 & 12.178 & 0.000 \\
Empowering Leadership & 0.240 & 0.026 & 9.293 & 0.000 \\
\hline
\end{tabular}

Dependent variable: Psychological Empowerment (PE)

Step 3: Multiple regression was conducted with the independent variable (EPL) and the mediator variable (PE) as the predictor variables. This regression estimation is done to obtain the path estimate denoted by $b$ (i.e. the direct effect between the mediator and the dependent variable) and c' (i.e. the direct effect of the independent variable on the dependent variable in the presence of the mediator variable). The result of the multiple regressions is presented in Table 6 , and Table 7.

Table 6. Coefficient Estimate of Multiple Regressions.

\begin{tabular}{|c|c|c|c|c|c|c|}
\hline Variables & Estimate & Std. Error & T Value & Sig. Value & Tolerance & VIF \\
\hline Constant & 4.777 & 2.089 & 2.287 & 0.024 & & \\
\hline Empowering Leadership & 0.030 & 0.014 & 2.076 & 0.040 & 0.633 & 1.580 \\
\hline Psychological Empowerment & 0.303 & 0.036 & 8.417 & 0.000 & 0.633 & 1.580 \\
\hline $\mathrm{R}$ & 0.712 & & & & & \\
\hline R-square & 0.507 & & & & & \\
\hline Adjusted R-square & 0.500 & & & & & \\
\hline F-change & 76.08 & & & & & \\
\hline Durbin-Watson & 1.840 & & & & & \\
\hline
\end{tabular}

Dependent variable: Voice Behavior

Model summary result of the multiple regression analysis presented in Table 6 shows R-square value of 0.507 , indicating that, the predictors in the model (EPL, PE) account for $50.07 \%$ of the variations in the dependent variable (VB) and error term accounted for the rest. The research model significance was also achieved with a Sigvalue of 0.000 . Durbin-Watson estimate was desirable with a value of 1.840 [56].

Table 7. ANOVA Table.

\begin{tabular}{llllll}
\hline Model & Sum of squares & df & Mean square & F & Sig \\
\hline Regression & 2532.059 & 2 & 1266.029 & 0.000 \\
Residual & 2462.749 & 148 & 16.640 & \\
Total & 4994.808 & 150 & & \\
\hline
\end{tabular}

Dependent Variable: VB Predictors: Constant, EPL, PE

Table 7 presents result of the ANOVA table, it shows a significance F-estimate of 76.083 with a Sig-value of 0.000 . This further indicates a significant model fit.

Step 4: Estimation and the test of indirect effect for statistical significance was done. There are several approaches to estimate the indirect effect, casual steps [55], Product of coefficients [57] and Difference in coefficients [57]. The study used the product of coefficients approach proposed by [58] to estimate the value of the indirect effect of EPL on VB. The estimated path coefficients are $\mathrm{a}=0.240$, $b=0.303$. The product of these two coefficients is the indirect effect, 0.0728 (approx. 0.073)

Next, the study tested the statistical significance of the indirect effect using percentile Bootstrapping approach as proposed by [59]. The Percentile Bootstrapping was preferred because it estimates confidence level based on simulated distribution and does not assume any level of normality. The syntax used was adopted from [59]. The results of the
Bootstrapping approach are presented in Figure 4.

The results show an estimate of the indirect effect to be 0.0727 (approx. 0.073). The indirect effect has an estimated standard error of 0.0117 . At the $95 \%$ confidence interval, zero (0) lies outside the estimated confidence boundary $(0.0499,0.0958)$. The estimated Z-value and P-value or Sigvalue is 6.2188 and 0.0000 respectively, indicating statistical significance of the indirect effect. The study could conclude that the indirect effect of EPL on VB via the intermediary variable $(\mathrm{PE})$ is statistically significance with a $\mathrm{p}$-value of 0.000 and an indirect effect value of 0.073 . Therefore, the findings support the research hypothesis 3 that Psychological empowerment acts as a significant mediator between Empowering leadership and Voice Behavior. The result in Table 6 further supports the research hypothesis two since there exist a significant relationship between Psychological empowerment and Voice Behavior. Figure 4 summarizes the hypothesis. 
H1

H2

H3

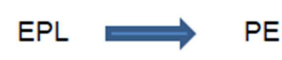

Mediation role of $\mathrm{PE}$

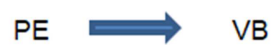

Decision

Support

Support

Support

Figure 4. Hypothesis Testing and Decision Arrived.

\section{Conclusion}

This research analyzes the effects of empowering leadership upon employee voice behavior with the mediating effect of psychological empowerment of the employees. Under the effect of empowering leadership, the employees are more motivated and have the autonomy to make their own decisions regarding the workplace and their job requirements. An empowering leader acts as a coach towards his employees and motivates them and supports them in their decisions as well as listen to their concerns. Therefore making the employees feel heard and understood which empowers them mentally and psychologically and encourages them to act and be more proactive in their jobs, thus contributing towards the greater organizational goal. Moreover, when the employees feel that they are heard, they become more confident about voicing out their opinions and concerns regarding their own jobs as well as the organization, thereby exhibiting voice behavior. Hence the research proves that there is positive correlation between all the three variables. This finding is summarized in Figure 4.

This research has implications in the academic sector as well as the industrial and organizational sector. Organizations can use it to employ empowering leadership and measure the change in the behavior of their employees, their attitude, their motivation, and their empowerment. In terms of academia, this research opens more doors to further investigate the relationship between these variables.

This research is also subject to some limitations. The research used random sampling and the technique employed for getting responses was completely quantitative. Future research can focus on one industry or one organization to get a better understanding of the effects of empowering leadership on employee voice behavior in that company. Moreover, qualitative techniques can be applied to gain an in-depth view of the employees' feelings and levels of empowerment. Also, these variables can be paired with other variables such as employee motivation, job satisfaction etc. to get a more holistic view of the effects of empowering leadership.

\section{Conflict of Interest}

All the authors declare that there is no conflict of interest.

\section{References}

[1] Ahearne, M., Mathieu, J., \& Rapp, A. (2005). To empower or not to empower your sales force? An empirical examination of the influence of leadership empowerment behavior on customer satisfaction and performance. Journal of Applied psychology, 90 (5), 945.

[2] Kirkman, B. L., \& Rosen, B. (1999). Beyond self-management: Antecedents and consequences of team empowerment. Academy of Management journal, 42 (1), 58-74.

[3] Chen, A. S. Y., \& Hou, Y. H. (2016). The effects of ethical leadership, voice behavior and climates for innovation on creativity: A moderated mediation examination. The Leadership Quarterly, 27 (1), 1-13.

[4] LePine, J. A., \& Van Dyne, L. (1998). Predicting voice behavior in work groups. Journal of applied psychology, 83 (6), 853 .

[5] Ng, T. W., \& Feldman, D. C. (2012). Employee voice behavior: A meta - analytic test of the conservation of resources framework. Journal of Organizational Behavior, 33 (2), 216-234.

[6] Premeaux, S. F., \& Bedeian, A. G. (2003). Breaking the silence: The moderating effects of self-monitoring in predicting speaking up in the workplace. Journal of management studies, 40 (6), 1537-1562.

[7] Duan, J. Y. (2011). The research of employee voice in Kirkman, B. L., \& Rosen, B. (1999). Beyond self-management: Antecedents and consequences of team empowerment. Academy of Management journal, 42 (1), 58-74.

[8] Maynes, T. D., \& Podsakoff, P. M. (2014). Speaking more broadly: An examination of the nature, antecedents, and consequences of an expanded set of employee voice behaviors. Journal of Applied Psychology, 99 (1), 87.

[9] Locke, E. A., Alavi, M., \& Wagner III, J. A. (1997). Participation in decision making: An information exchange perspective.

[10] Morrison, E. W. (2011). Voice and silence within organizations: Literature review and directions for future research. Academy of Management annals, 5 (1), 373-412.

[11] Duan, J., \& Zhong, J. (2005). Voice behavior in organization. Psychol. Sci, 28, 69-71.

[12] Song, J., Wu, J., \& Gu, J. (2017). Voice behavior and creative performance moderated by stressors. Journal of Managerial Psychology.

[13] Arnold, J. A., Arad, S., Rhoades, J. A., \& Drasgow, F. (2000). The empowering leadership questionnaire: The construction and validation of a new scale for measuring leader behaviors. Journal of organizational behavior, 21 (3), 249-269.

[14] Bharadwaja, M., \& Tripathi, N. (2020). Linking empowering leadership and job attitudes: The role of psychological empowerment. Journal of Asia Business Studies.

[15] Bartunek, J. M., \& Spreitzer, G. M. (2006). The interdisciplinary career of a popular construct used in management: Empowerment in the late 20th century. Journal of Management Inquiry, 15 (3), 255-273. 
[16] Hill, F., \& Huq, R. (2004). Employee empowerment: Conceptualizations, aims and outcomes. Total Quality Management \& Business Excellence, 15 (8), 1025-1041.

[17] Fernandez, S., \& Moldogaziev, T. (2011). Empowering public sector employees to improve performance: Does it work? The American Review of Public Administration, 41 (1), 23-47.

[18] Humphrey, S. E., Nahrgang, J. D., \& Morgeson, F. P. (2007). Integrating motivational, social, and contextual work design features: A meta-analytic summary and theoretical extension of the work design literature. Journal of Applied Psychology, 92 (5), 1332-1356.

[19] Parker, S. K., Wall, T. D., \& Cordery, J. L. (2001). Future work design research and practice: Towards an elaborated model of work design. Journal of Occupational \& Organizational Psychology, 74 (4), 413-440.

[20] Pearce, C. L., Sims Jr., H. P., Cox, J. F., Ball, G., Schnell, E., Smith, K. A., \& Trevino, L. (2003). Transactors, transformers and beyond: A multi-method development of a theoretical typology of leadership. Journal of Management Development, $22(4), 273-307$.

[21] Conger, J. A., \& Kanungo, R. N. (1988). The empowerment process: Integrating theory and practice. Academy of Management Review, 13 (3), 471-482.

[22] Vecchio, R. P., Justin, J. E., \& Pearce, C. L. (2010). Empowering leadership: An examination of mediating mechanisms within a hierarchical structure. The Leadership Quarterly, 21 (3), 530-542.

[23] Thomas, K. W., \& Velthouse, B. A. (1990). Cognitive elements of empowerment: An "interpretive" model of intrinsic task motivation. Academy of Management Review, 15 (4), 666-681.

[24] Spreitzer, G. M. (1995). Psychological empowerment in the workplace: Dimensions, measurement, and validation. Academy of management Journal, 38 (5), 1442-1465.

[25] Brief, A. P., \& Nord, W. R. (1990). Work and meaning: Definitions and interpretations.

[26] Hackman, J. R., Hackman, R. J., \& Oldham, G. R. (1980). Work redesigns (Vol. 2779). Reading, Mass.: AddisonWesley.

[27] Gist, M. E. (1987). Self-efficacy: Implications for organizational behavior and human resource management. Academy of management review, 12 (3), 472-485.

[28] Deci, E. L., Connell, J. P., \& Ryan, R. M. (1989). Selfdetermination in a work organization. Journal of applied psychology, 74 (4), 580.

[29] Bell, N. E., \& Staw, B. M. (1989). 11 People as sculptors versus sculpture: the roles of personality and personal control. Handbook of career theory, 232.

[30] Spector, P. E. (1986). Perceived control by employees: A meta-analysis of studies concerning autonomy and participation at work. Human relations, 39 (11), 1005-1016.

[31] Ashforth, B. E. (1989). The experience of powerlessness in organizations. Organizational behavior and human decision processes, 43 (2), 207-242.

[32] Martinko, M. J., \& Gardner, W. L. (1982). Learned helplessness: An alternative explanation for performance deficits. Academy of Management Review, 7 (2), 195-204.

[33] Van Dyne, L., \& LePine, J. A. (1998). Helping and voice extra-role behaviors: Evidence of construct and predictive validity. Academy of Management journal, 41 (1), 108-119.

[34] Hunton, J. E., Hall, T. W., \& Price, K. H. (1998). The value of voice in participative decision making. Journal of Applied Psychology, 83 (5), 788.

[35] Seibert, S. E., Wang, G., \& Courtright, S. H. (2011). Antecedents and consequences of psychological and team empowerment in organizations: a meta-analytic review. Journal of applied psychology, 96 (5), 981.

[36] Bandura, A. (2001). Social cognitive theory: An agentic perspective. Annual review of psychology, 52 (1), 1-26.

[37] Pigeon, M., Montani, F., \& Boudrias, J. S. (2017). How do empowering conditions lead to empowered behaviours? Test of a mediation model. Journal of Managerial Psychology.

[38] Zhang, X., \& Bartol, K. M. (2010). Linking empowering leadership and employee creativity: The influence of psychological empowerment, intrinsic motivation, and creative process engagement. Academy of management journal, 53 (1), 107-128.

[39] Fong, K. H., \& Snape, E. (2015). Empowering leadership, psychological empowerment and employee Outcomes: Testing a multi - level mediating model. British Journal of Management, 26 (1), 126-138.

[40] Liden, R. C., Wayne, S. J., \& Sparrowe, R. T. (2000). An examination of the mediating role of psychological empowerment on the relations between the job, interpersonal relationships, and work outcomes. Journal of Applied Psychology, 85 (3), 407-416.

[41] Dansereau Jr, F., Graen, G., \& Haga, W. J. (1975). A vertical dyad linkage approach to leadership within formal organizations: A longitudinal investigation of the role making process. Organizational behavior and human performance, 13 (1), 46-78.

[42] Duan, J. Y., \& Zhang, Q. (2012). The study of voice behavior in the perspective of cognition: cognitive factors, theoretical basis and formation mechanism. Advances in Psychological Science, 20 (1), 115-126.

[43] Dulebohn, J. H., Bommer, W. H., Liden, R. C., Brouer, R. L., \& Ferris, G. R. (2012). A meta-analysis of antecedents and consequences of leader-member exchange: Integrating the past with an eye toward the future. Journal of management, 38 (6), 1715-1759.

[44] Bae, K. S., Chuma, H., Kato, T., Kim, D. B., \& Ohashi, I. (2011). High performance work practices and employee voice: A comparison of Japanese and Korean workers. Industrial Relations: A Journal of Economy and Society, 50 (1), 1-29.

[45] Seibert, S. E., Silver, S. R., \& Randolph, W. A. (2004). Taking empowerment to the next level: A multiple-level model of empowerment, performance, and satisfaction. Academy of management Journal, 47 (3), 332-349.

[46] Raub, S., \& Robert, C. (2012). Empowerment, organizational commitment, and voice behavior in the hospitality industry: Evidence from a multinational sample. Cornell Hospitality Quarterly, 54, 136-148. 
[47] Amundsen, S., \& Martinsen, Ø. L. (2014). Empowering leadership: Construct clarification, conceptualization, and validation of a new scale. The leadership quarterly, 25 (3), 487-511.

[48] Kaiser, H. F. (1974). An index of factorial simplicity. Psychometrika, 39 (1), 31-36.

[49] Lee Rodgers, J., \& Nicewander, W. A. (1988). Thirteen ways to look at the correlation coefficient. The American Statistician, 42 (1), 59-66.

[50] Wackerly, D. D., Mendenhall III, W., Scheaffer, R. L. (2008). Multivariate Probability distributions. In: mathematical statisticswith Applications. 7th ed. Belmont, CA: Brooks/cole 223-295.

[51] Overholser, B. R., \& Sowinski, K. M. (2008). Biostatistics primer: part 2. Nutrition in Clinical Practice, 23 (1), 76-84.

[52] Mukaka, M. M. (2012). A guide to appropriate use of correlation coefficient in medical research. Malawi medical journal, 24 (3), 69-71.

[53] Yoo, W., Mayberry, R., Bae, S., Singh, K., He, Q. P., \& Lillard Jr, J. W. (2014). A study of effects of multicollinearity in the multivariable analysis. International journal of applied science and technology, 4 (5), 9.
[54] Bland, J. M., Altman, D. G. (1997). Statistics notes: Cronbach's alpha. https://doi.org/10.1136/bmj.314.7080.572

[55] Baron, R. M., \& Kenny, D. A. (1986). The moderatormediator variable distinction in social psychological research: Conceptual, strategic, and statistical considerations. Journal of personality and social psychology, 51 (6), 1173.

[56] Field, A. (2009). Discovering statistics using SPSS: (and sex and drugs and rock'n'roll)(ed.). London, Royaume-Uni: Sage.

[57] MacKinnon, D. P., \& Dwyer, J. H. (1993). Estimating mediated effects in prevention studies. Evaluation Review, 17, 144-158.

[58] MacKinnon, D. P., Warsi, G., \& Dwyer, J. H. (1995). A simulation study of mediated effect measures. Multivariate Behavioral Research, 30, 41-62.

[59] Preacher, K. J., \& Hayes, A. F. (2004). SPSS and SAS procedures for estimating indirect effects in simple mediation models. Behavior Research Methods, Instruments, \& Computers, 36, 717-731. 